\title{
MOBILIDADE E EROSÃO DA ENSEADA DA PRAIA DO MORRO, GUARAPARI - ES, EM DIFERENTES ESCALAS DE TEMPO
}

\section{MOBILITY AND EROSION OF THE PRAIA DO MORRO BAY, GUARAPARI - ES, AT CONTRASTING TIME SCALES}

\author{
Leonardo Azevedo Klumb Oliveira \\ Departamento de Geografia, Universidade Federal do Rio de Janeiro \\ Av. Athos da Silveira Ramos, 274. Prédio do Centro de Ciências Matemáticas e da Natureza, Bloco F, Ilha do Fundão. \\ CEP: 21.941.916 Brasil \\ E-mail: leoklumb@gmail.com
}

Jacqueline Albino

Departamento de Oceanografia e Ecologia, Universidade Federal do Espírito Santo. Av. Fernando Ferrari, 514 Goiabeiras Vitoria ES. CEP: 29075-910. Brasil

E-mail: albino.jacqueline@gmail.com

\section{Informações sobre o Artigo}

Data de Recebimento:

$11 / 10 / 2011$

Data de Aprovação:

$23 / 09 / 2013$

\section{Palavras-chave:}

Variações da linha de costa, morfodinâmica praial, modelo parabólico da enseada.

\section{Keywords:}

Embayed beaches, shoreline changes, beach morphodynamic, parabolic bay shape

\section{Resumo}

A mobilidade de praia ocorre em diversas escalas temporais e sua melhor compreensão se dá pela análise integrada dos diferentes processos atuantes na costa em sua escala de eventos. No município de Guarapari (ES), características naturais em nível regional e local somaram-se a problemas decorrentes da ocupação e uso da orla marítima, acentuando processos de erosão costeira. Neste aspecto, este trabalho se propôs a avaliar as alterações da linha de costa da Praia do Morro (Guarapari - ES), em seus aspectos físicos naturais. A análise das variações ocorreu de forma à contemplar as escalas multidecadal, decadal e anual. A obtenção dos dados foi realizada através de aerofotos, nas quais foram utilizadas técnicas de geoprocessamento, aplicação de modelos computacionais de predição de enseada e por meio da aplicação de métodos de obtenção de dados morfodinâmicos in loco, este último em um período de 1 ano de monitoramento. As maiores taxas de mobilidade no intervalo decadal se manifestaram nas extremidades do arco da praia, entre 1970 e 1978; entretanto, para o intervalo de 1970 a 2007, as taxas de mobilidade mantiveram-se basicamente constantes. Ao final, foi possível encontrar validação metodológica entre as diferentes escalas abordadas e inferir diagnósticos com base nos resultados obtidos.

\section{Abstract}

Shoreline changes occur at various scales and a better understanding is given by 
the integrated analysis of the various processes acting on the coast in its scale of events. In the littoral of Guarapari (ES), natural features in regional and local levels amounted to problems arising from occupation and use of the coast, causing pronounced processes of coastal erosion. In this respect, this study aimed to evaluate the natural changes in shoreline from Praia do Morro (Guarapari - ES), which has been significant erosion. The analysis of changes occurred in order to include annual, decadal and multidecadal scale. Data collection was conducted through aerial photographs, which were used in geoprocessing techniques, application of computational models to predict beach stabilization and by the application of methods for obtaining data morphodynamic, the latter in a period of 1 year of monitoring. The highest mobility rates in the range decadal manifested in the beach ends, between 1970 and 1978, however, for the interval from 1970 to 2007, mobility rates have remained basically constant. At the end, methodological validation was found between different scales addressed, and inferred diagnoses based on the results obtained.

\section{Introdução}

O contínuo incremento da ocupação da orla marítima aliado aos prejuízos econômicos, tanto materiais quanto na prestação de serviços, oriundos dos eventos de erosão de praia, destacam o papel de proteção das praias arenosas e expandem a necessidade da avaliação de sua mobilidade em relação à escala temporal dos eventos climáticos e oceanográficos.

Praias de enseada experimentam processos rotacionais e são consideradas mais estáveis em longo prazo. Para Hsu e Evans (1989) e Short (1999), praias de enseada podem apresentar diferentes graus de exposição às ortogonais predominantes de ondas, e desse modo, caracterizam-se como praias expostas, semi-abrigadas ou abrigadas. O grau de exposição condiciona a competência das correntes costeiras para o transporte de sedimentos, o que, para Short (1999), submete a enseada a um comportamento cíclico de erosão, transporte e deposição, em função das variações sazonais de incidência de ondas. Tal processo pode ocorrer em escala de semanas, meses ou décadas, sem, contudo, apresentar incremento ou decréscimo líquido de sedimentos no sistema (KLEIN et al, 2005).

Para a avaliação da mobilidade da praia é necessária a análise em diferentes escalas, desde a anual até a escala multidecadal, em função dos processos de maior abrangência temporal e a determinação de possíveis padrões de variação, sobretudo quando se trata de praia de enseada. As variações no clima de ondas, que respondem aos processos climáticos sazonais causam alterações no estado de equilíbrio de praias de enseada (SHORT \& MASSELINK, 1999), que tendem a ajustar seu perfil a um novo estado de equilíbrio.

O presente trabalho se propõe a determinar a mobilidade da praia do Morro, praia de enseada e balneário turístico do estado do Espírito Santo, frente às alterações meteo-oceanográficas impostas na escala anual, decadal e multidecadal, em um intervalo de 30 anos, a partir de levantamentos de dados campo e emprego de ferramentas matemáticas e conceituais de fácil compreensão. Os resultados permitirão iniciar a discussão sobre os impactos e/ou danos na orla e contribuir nos futuros planos de intervenção e gerenciamento costeiro do Município.

\section{Área de Estudo}

A Praia do Morro, situada no balneário turístico de Guarapari, no setor centro-sul do estado do Espírito Santo é praia integrante do Programa Turístico Estadual «Rota do Sol». Bastante procurada como balneário, a praia possui importante papel na oferta de bens e serviços naturais e econômicos para o município, o qual recebe uma demanda populacional de turistas no verão de aproximadamente $400 \%$ em relação à sua população fixa (IBGE, 2010). Em abril de 2010, em consequência de um evento de forte frente fria, associada ao incremento da energia de ondas, a praia sofreu forte erosão, com grande perda material da estrutura de quiosques e muros do calçadão.

A praia do Morro (Figura 1), com uma 
extensão de aproximadamente $3 \mathrm{~km}$ e orientação NE - SW encontra-se na porção do litoral capixaba onde o embasamento cristalino Pré-Cambriano alcança a linha de costa, a partir da região serrana interiorana do estado e apresenta um litoral recortado com inúmeras praias de enseada. O segmento de litoral possui baixo aporte sedimentar continental, plataforma continental estreita e alta energia de ondas (ALBINO e OLIVEIRA, 2001). A porção submersa da enseada (Figura 2) apresenta um menor gradiente de profundidade em seu setor SW, caracterizando batimetria ligeiramente mais plana e rasa; rumo NE, há um aumento do gradiente de inclinação, caracterizando um setor levemente inclinado e mais profundo.

A Praia do Morro está inserida na bacia hidrográfica de Guarapari e realiza trocas sedimentares sazonais com o estuário conhecido como Canal de Guarapari, cuja foz situa-se adjacente

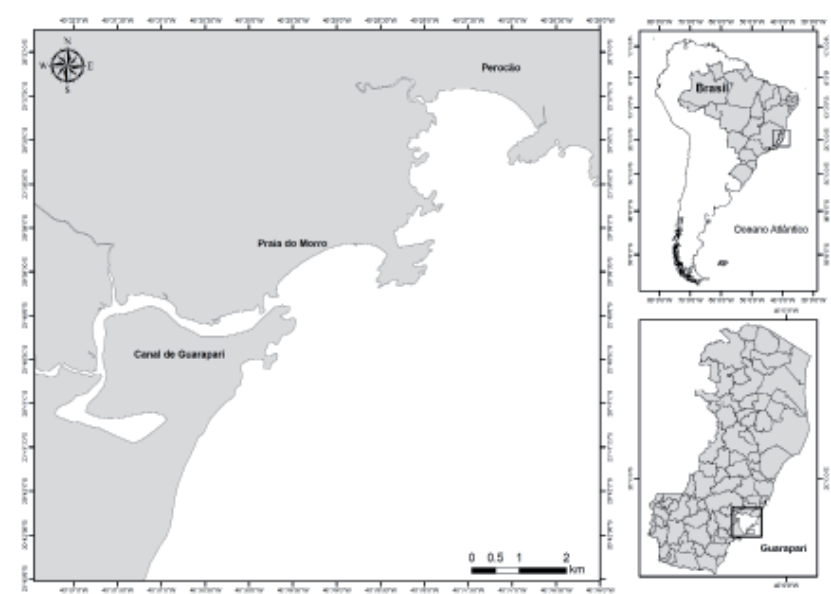

Figura 1 - Representação esquemática da área de estudo.

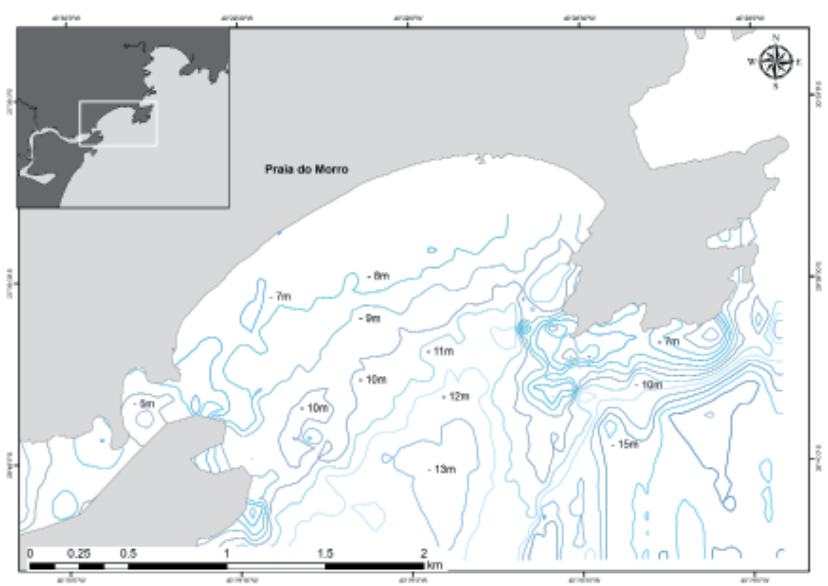

Figura 2- Batimetria da Praia do Morro e região adjacente. ao setor SW da praia. O clima é quente e úmido pela classificação de Koppen (PEEL et al, 2007), com maior incidência de chuvas durante o verão e estação seca no outono e inverno. Os índices pluviométricos registram maior intensidade de precipitações nos meses de outubro a janeiro, com média pluviométrica $1800 \mathrm{~mm} / \mathrm{ano}$. A temperatura média anual é de $25^{\circ} \mathrm{C}$ (INCAPER, 2011).

De acordo com dados de reanálise de ondas sintetizados por Piumbini (2009), a direção das ondas incidentes, sob condições de tempestade (Figura 3), é proveniente dos quadrantes S/SE, com alturas de maior frequência entre 1,5 e $3 \mathrm{~m}$ e períodos entre 10 e $11 \mathrm{~s}$, eventualmente causando danos à estrutura física das calçadas e quiosques (Figura 4, a-c). Em condições de tempo bom, as ondas aproximam-se de E/NE, com alturas médias de $1,5 \mathrm{~m}$ e períodos entre $7-9$ segundos, geralmente reconstruindo a feição da praia (Figura 4, d-f).

Em uma escala multidecadal, as ondas provenientes dos quadrantes $\mathrm{S} / \mathrm{SE}$ são mais recorrentes no litoral (Figura 5), o que demonstra seu elevado potencial de interferência nos processos costeiros praiais e modelagem da forma da praia em larga escala temporal.

\section{Materiais e Métodos}

A mobilidade da praia foi analisada por dois métodos e para diferentes escalas:

Morfodinâmica e mobilidade transversal e longitudinal de praia na escala anual;

Evolução em planta da praia em escala decadal e multidecadal e planta modelada

\subsection{Análise morfodinâmica}

Foram definidas cinco estações amostrais, distribuídas entre os três setores da praia - SW, Central e NE - onde foram levantados perfis topográficos bimensais, transversais à linha de praia (Figura 6), pelo período de um ano (outubro 2008 a outubro 2009). A escala temporal de um ano de amostragem foi escolhida no sentido de abranger os ciclos sazonais da praia, destacadamente um ciclo de inverno e um ciclo de verão, os quais representam as maiores variações hidrodinâmicas e morfológicas da praia. 

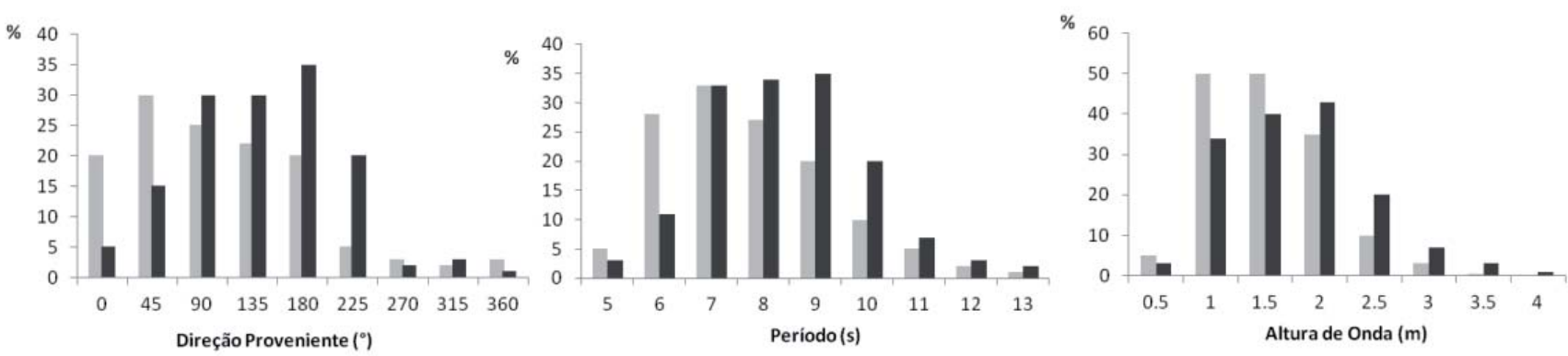

-Condiç̄es de Tempo Bom

Figura 3 - Clima de ondas para a costa do Espírito Santo, sob condições de verão e inverno. Adaptado de Piumbini, 2009.
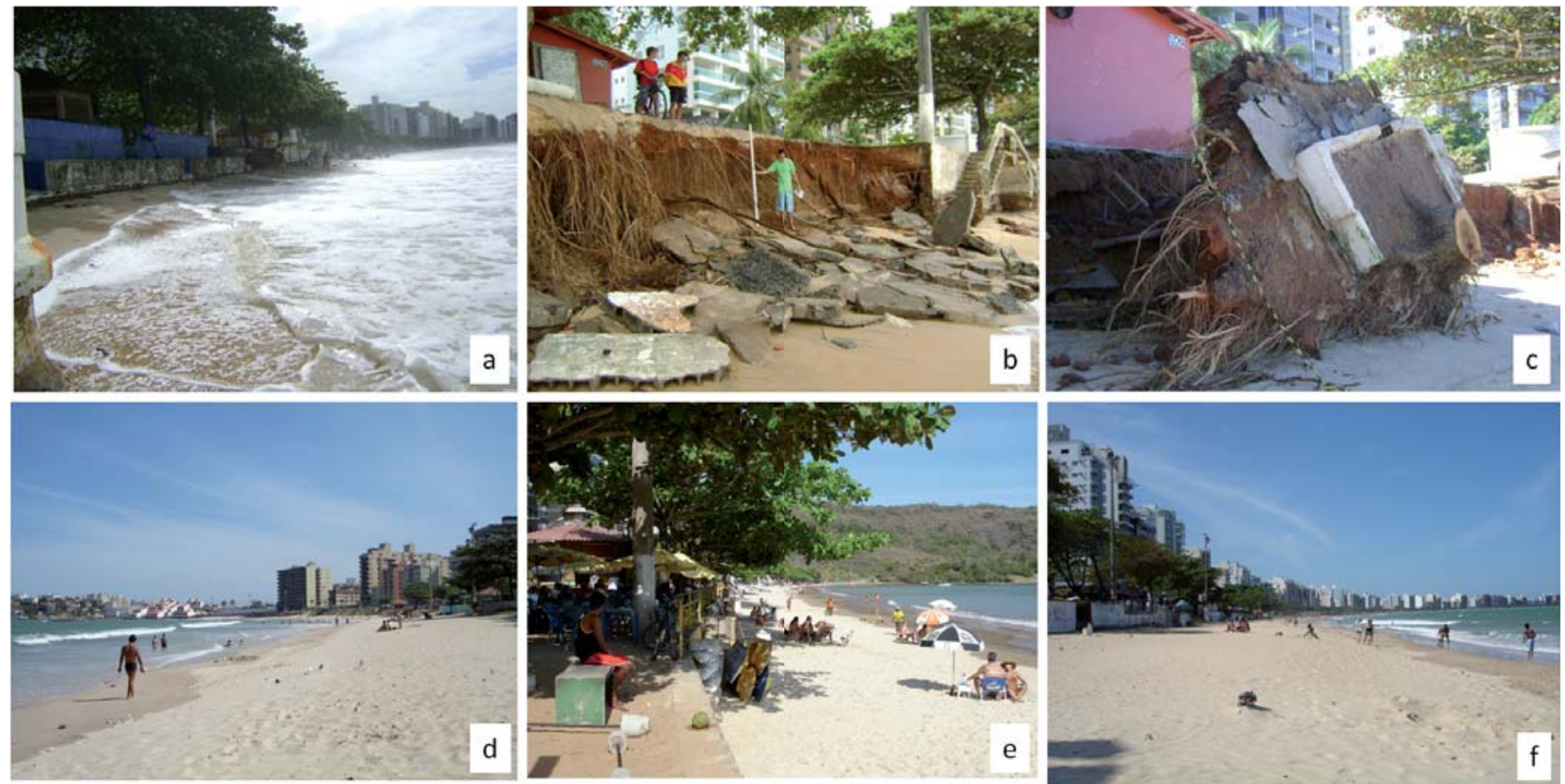

Figura 4- (a-c): Praia do Morro sob evento de ondas de SE, associada a intensa frente fria em abril/2010. Muros e calçadas destruídos; (d-f): a praia sob condições de ondas de E-NE, associada aos alísios, em janeiro 2010, menos intensos e mais frequentes. Fotos dos autores.

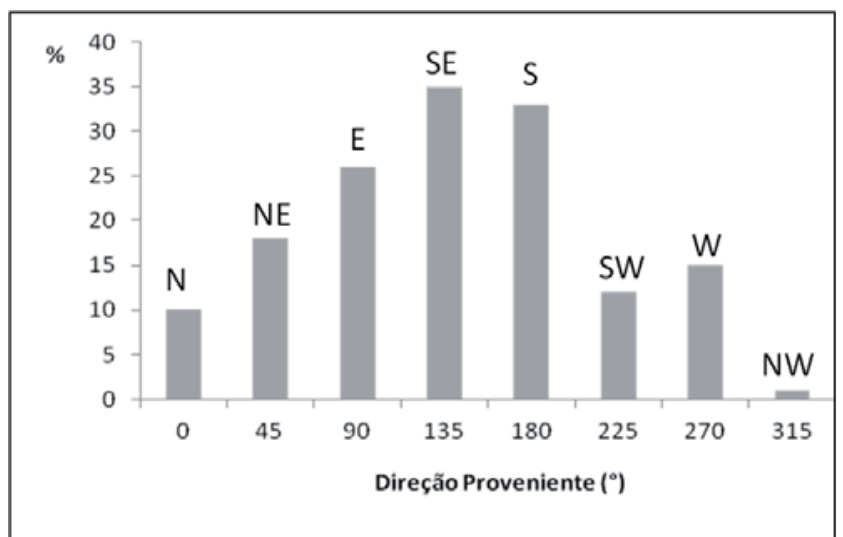

Figura 5 - Histograma de direção média de onda entre os anos de 1957-2002 para costa do Espírito Santo. Adaptado de Piumbini, 2009.
Para tanto, utilizou-se o método topográfico de perfilagem aérea, o qual, utilizando-se equipamentos de nível de precisão, mira graduada e trena laser, foram medidas as cotas altimétricas com precisão decimal de perfis transversais à praia, a partir de um ponto fixo georreferenciado, rumo ao mar, até a profundidade média da quebra das ondas. As areias da berma e face praial foram coletadas e tratadas pelo método de peneiramento à seco proposto por Folk (1968) e classificadas quanto a granulometria segundo Folk e Ward (1957). Os resultados foram utilizados em modelos de transporte de sedimentos e determinação de parâmetros morfodinâmicos.

Como traçador de rumos das correntes de deri- 
va litorânea e consequente transporte sedimentar foi utilizado o método proposto por Taggart e Schwartz (1988), modificado por Souza (2007). O método consiste na interpretação de cinco parâmetros: (1) largura da praia; (2) Inclinação da face de praia; (3) diâmetro médio dos grãos constituintes da face praial; (4) curtose (5) desvio padrão. O método considera que de uma área em erosão para uma área em deposição, os indicadores apresentam o seguinte comportamento: aumento da largura da praia, afinamento e melhoramento no grau de seleção granulométrico, menor ângulo de inclinação da face e menor energia hidrodinâmica.

A partir de então, utilizando-se uma matriz de comparação, cada amostra de cada estação foi comparada com as duas amostras de estações adjacentes (anterior e posterior), sendo o produto da comparação indicado com sinal $(+)$ indicador de deposição; ou (-) como indicador de erosão.

Para cada um dos cinco indicadores analisados, foi obtido um par de sinais, podendo ser $(+/+)$, $(+/-),(-/+),(-/-)$, uma vez que cada amostra foi comparada com suas duas adjacentes, com exceção das amostras das extremidades das praias. $\mathrm{O}$ resultado final foi dado pela comparação de todos os indicadores, de forma que $(+/+)$, significa uma predominância de processos deposicionais no local; $(-/-)$, indica predomínio de erosão no segmento considerado; (+/-) e (-/+) são indicativos de área com predomínio de transporte sedimentar, considerado como zona de by-pass.

Os parâmetros morfodinâmicos obtidos fundamentaram a determinação da tipologia praial, o grau de exposição e o estado morfodinâmico no momento da observação.

Para determinação da tipologia da praia foi utilizado o método de superposição de perfis e aplicação do parâmetro $\Omega$ de Dean (1973):

$$
\Omega=\frac{H b}{w S * T}
$$

No qual $H b$ é a altura da onda na arrebentação (m), ws é a velocidade de decantação do grão na face da praia $(\mathrm{cm} / \mathrm{s})$ e $T$ é o período do trem de ondas (s). Neste trabalho foram calculados valores para estabelecer a tipologia da praia em condições

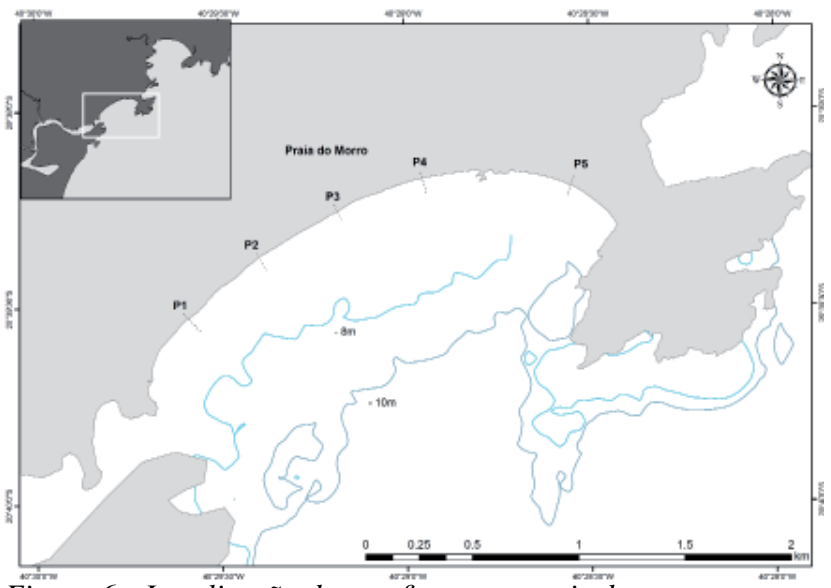

Figura 6 - Localização dos perfis transversais de amostragem ao longo do arco praial.

de tempo bom e tempestade, considerando-se os valores de altura e período de ondas significativas obtidos de CPTEC/INPE (2010). O valor da variável ws foi atribuído de acordo com modelo de decantação de grãos na face da praia conforme descrito por Muehe (1996). A partir do valor de $\mathbf{\Omega}$ obtido, foram determinadas as tipologias referentes a cada estação amostral, conforme adaptação dada por Wright et al (1985) (Quadro 1).

\subsection{Mobilidade em planta}

\subsubsection{Modelo de planta em equilíbrio}

Para o diagnóstico da mobilidade em planta foram utilizados o modelo parabólico para praias de enseada e a análise de fotografias aéreas multidecadais georreferenciadas e tratadas em ambiente SIG, com posterior utilização na ferramenta Digital Shoreline Analysis System (DSAS) para ArcGis 9.3 de acordo com metodologia de THIELER et al, 2009.

Quadro 1 - Estados modais de praia conforme interpretação de $\Omega$. Adaptado de Wright et al (1985).

\begin{tabular}{|l|c|c|}
\hline \multicolumn{1}{|c|}{ Estado Praial } & $\Omega$ médio & Desvio Padrão \\
\hline Refletivo & $<1,5$ & - \\
\hline Terraço de Baixa Mar & 2,4 & 0,19 \\
\hline Banco Transversal & 3,15 & 0,64 \\
\hline Banco de Praia Ritmico & 3,5 & 0,76 \\
\hline Bancoe Calha Longitudinal & 4,7 & 0,93 \\
\hline Dissipativo & $>5,5$ & - \\
\hline
\end{tabular}


O modelo parabólico tem como princípio sua aplicação em uma praia em equilíbrio estático, onde o trem de ondas predominante ataca ortogonalmente a costa, refratando em um promontório, natural ou obra de engenharia. A configuração assumida para o modelo é que o promontório dá origem a uma zona de sombra onde a forma da equação da espiral logarítmica aproxima-se da forma da costa (HSU \& EVANS, 1989; SHORT, 1999).

Para a determinação do estado de equilíbrio da enseada utilizou-se a equação básica do modelo parabólico proposta por Hsu \& Evans (1989) e Hsu et al (2008) e, por meio do software livre MEPPE (Modelo de Equilíbrio em Planta para Praias de Enseada), conforme descrito por Vargas et al (2002). Como pontos controle, foram escolhidos: i) a extremidade $\mathrm{N}$ da praia, como ponto de difração $\mathrm{NE}$; ii) a extremidade $\mathrm{S}$, como ponto de difração $\mathrm{SW}$; iii) um ponto proximal, no meio do arco de praia, como o início da porção retilínea em relação às duas extremidades, de acordo com a metodologia do modelo (Figura 7).

\subsubsection{Variação histórica da Linha de Costa}

Para sugerir a variação da linha de costa nos últimos 40 anos foram utilizadas imagens aéreas da Praia do Morro em intervalos de 08 e 37 anos, correspondentes aos anos de 1970 e 1978, verticais e monocromáticas e do ano de 2007, do mosaico fotogramétrico aéreo digital do Espírito Santo, georreferenciado originalmente em UTM, WGS

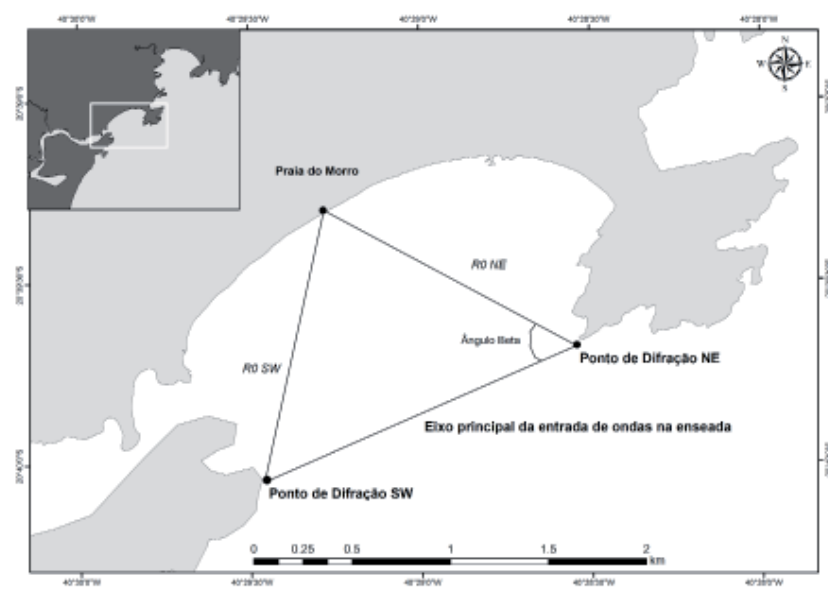

Figura 7 - Definição dos Pontos Controle na Praia do Morro para aplicação do modelo parabólico de Hsu e Evans (1989).
1984, Zona 24S. As imagens de 1970 e 1978 foram cedidas pelo Instituto de Desenvolvimento Florestal do Espírito Santo (IDAF) e o mosaico aéreo de 2007 pelo Instituto Estadual de Meio Ambiente do Espírito Santo (IEMA). As mais antigas são produtos de imagens analógicas, digitalizadas com resolução de 600 dpi, em formato JPEG.

Todo o material fotográfico foi transformado para extensão TIFF e georreferenciado no programa Arcgis 9.3 ${ }^{\circledR}$ tendo como base o mosaico de 2007. A representatividade do pixel variou entre 0.7 e 1.7 metros. Para o georreferenciamento e retificação geométrica das demais imagens foram escolhidos vinte e dois pontos controle próximos da área de interesse (linha de costa). A partir do georreferenciamento foi escolhido o indicador mais adequado à área, neste caso, a linha de preamar média (LPM), a qual é determinada pela linha de sedimentos secos/ molhados, devido a maior facilidade de identificação nas imagens, conforme sugerido por Absalonsen e Toldo Jr. (2006). A partir de então foram traçadas manualmente as linhas de costa de cada ano, em formato shapefile para posterior sobreposição para fins de comparação. Uma vez delimitadas as linhas de preamar das imagens, optou-se, para melhor adequação gráfica, representá-las em figura, vetorizada em polígono a partir das imagens aéreas, tomando-se a calçada como referencial base da linha de costa (Figura 8).

$\mathrm{O}$ erro em relação à amplitude da maré foi estimado com base no cálculo da variação média entre maré alta de sizígia $(1,5 \mathrm{~m})$ e quadratura $(1,2 \mathrm{~m})$ na região, por meio da utilização de dados históricos de maré retirados de DHN, 2011. Como base de cálculo, utilizou-se o valor de $0,3 \mathrm{~m}$ como amplitude entre as marés, aplicado em relação ao gradiente da face praial calculado para cada Estação (Quadro 2). Por fim, calculou-se uma média entre as variações, obtendo-se como valor de erro médio, $6 \mathrm{~m}$.

Os cálculos de variação da linha de costa foram feitos quantificando-se, em planta, a distância entre as linhas previamente obtidas. Para tanto, foram delimitados automaticamente 62 transectos longitudinais ao longo do arco da Praia do Morro, com distância de aproximadamente 30 metros entre eles, através da ferramenta computacional 


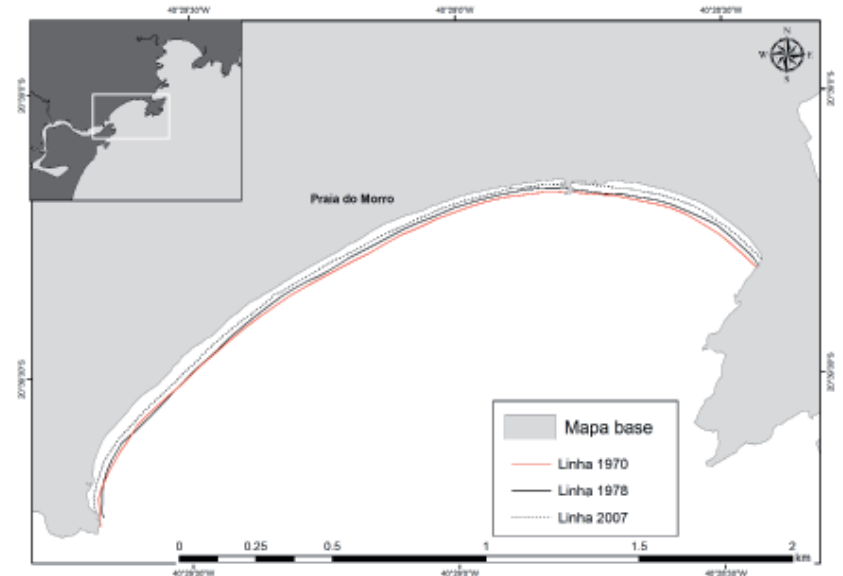

Figura 8 - Representação esquemática das linhas de preamar dos anos 1970, 1978 e 2007 para fins de análise da variação da linha de costa na Praia do Morro.

Quadro 2 - Inclinação da face e amplitude entre sizígia e quadratura por Estação para estimativa de cálculo do erro médio da maré.

\begin{tabular}{|c|c|c|}
\hline Estação & Inclinação da Face & Amplitude Siz/Quad \\
\hline P1 & $01: 14$ & $4,2 m$ \\
\hline P2 & $01: 15$ & $4,5 m$ \\
\hline P3 & $01: 18$ & $5,5 m$ \\
\hline P4 & $01: 21$ & $6,3 m$ \\
\hline P5 & $01: 30$ & $9 m$ \\
\hline
\end{tabular}

Digital Shoreline Analysis System (DSAS) versão 4.2, através do aplicativo Net Shoreline Movement, (THIELER et al, 2009). A linha de base, utilizada na referência espacial de todos os transectos, consistiu numa linha paralela a avenida litorânea da praia e distante aproximadamente 100 metros sentido continente (Figura 9).

\section{Resultados e Discussão}

\subsection{Morfodinâmica praial}

\subsubsection{Mobilidade Topográfica}

Os perfis topográficos plotados e sobrepostos das campanhas aparecem na Figura 10.

$\mathrm{O}$ setor SW (P1 e P2) demonstrou maior mobilidade entre os meses de dezembro e junho, respectivamente representativos de verão e inverno, apresentando feição mais construtiva no verão e uma tendência erosiva no inverno. Nos meses de outubro, abril e agosto, houve baixa mobilidade vertical nos perfis. Para o mês de fevereiro, o setor

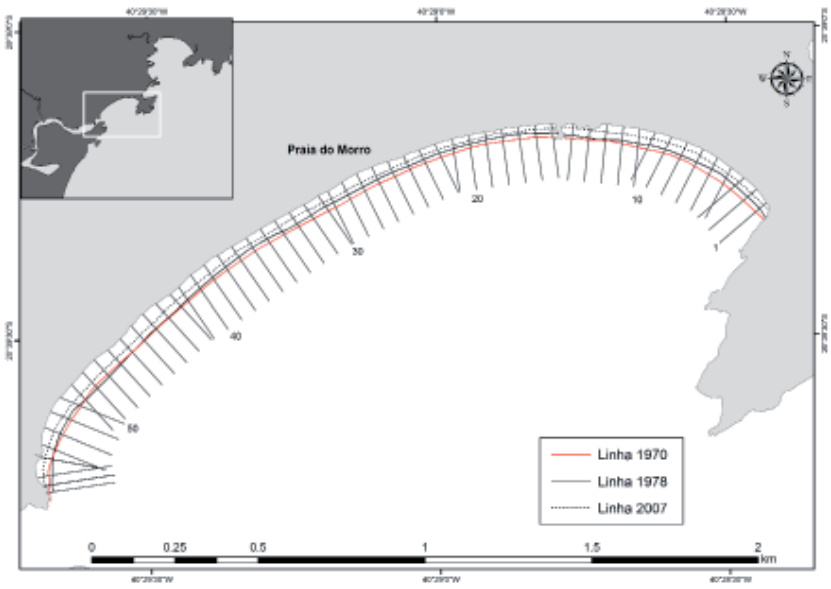

Figura 9 - Distribuição dos transectos ao longo da praia, como base para quantificação das variações da linha de costa ao longo das décadas.

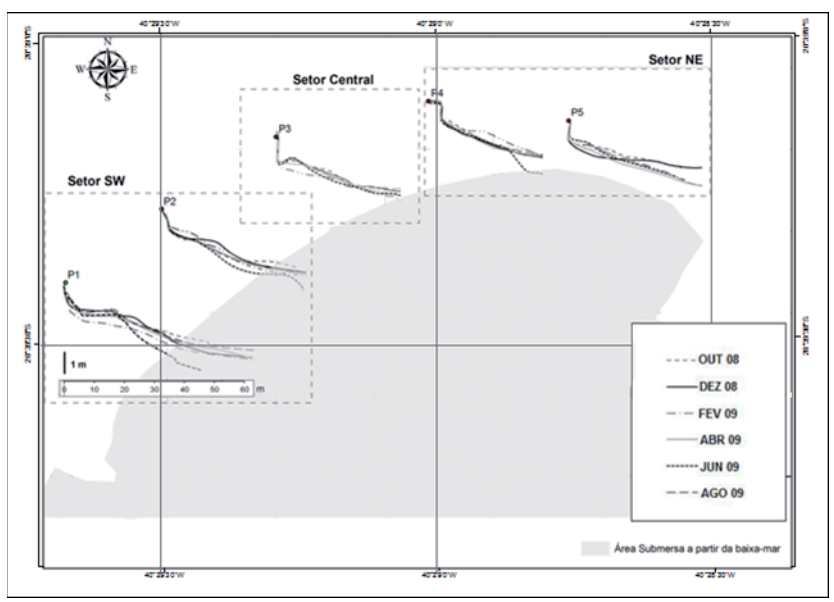

Figura 10- Resultado da medição dos perfis transversais realizados nas campanhas.

apresentou uma perda de volume, provavelmente associada a eventos hidrodinâmicos.

O setor Central (P3) apresentou-se praticamente estável durante o ano, não demonstrando variações significativas em termos de volume de sedimentos. Para o setor NE (P4 e P5), com exceção dos meses de fevereiro e junho, a estação P4 apresentou muito baixa mobilidade morfodinâmica, muito semelhante ao Setor Central, mantendo-se constante ao longo do ano. Notadamente em junho, pôde-se observar um perfil erosivo, com aparente perda de sedimentos, haja vista ser o mês de maior incidência de frentes frias. Já para fevereiro, observa-se aumento do volume sedimentar na zona emersa. A estação P5 apresentou moderada mobilidade topográfica no perfil. Notadamente, a maior amplitude de volume ocorreu entre os me- 
ses de outubro e abril. Para o mês de dezembro, pode-se notar um incremento no volume de areia na face praial.

\subsubsection{Variação Granulométrica}

De uma maneira geral a Praia do Morro é caracterizada por areias finas, com bom grau de seleção. Observa-se aumento no grau de seleção longitudinalmente à praia, de SW para NE assim como um afinamento granulométrico do Setor SW mais exposto ao Setor NE.

Observa-se uma variação sazonal associada ao clima de ondas. No verão, no setor SW, predominavam na estação P1 areias finas $(80,7 \%)$, seguido de areias médias (12,2\%), enquanto para o NE verificou-se predominância de areias muito finas $(51,1 \%)$ seguido de areias finas $(47,1 \%)$, e observou-se melhor grau de seleção de P1 $(\sigma 0,463)$ para P5 $(\boldsymbol{\sigma} 0,398)$.

No inverno, no setor SW, predominaram areias grossas $(33,8 \%)$ e médias $(28 \%)$, e uma notável diminuição granulométrica para NE (P5), que apresentou predomínio de areias finas $(58,7 \%)$ e muito finas $(41,1 \%)$, além de melhoramento no grau de seleção, de $(\boldsymbol{\sigma} 0,93)$ em P1, para $(\boldsymbol{\sigma} 0,31) \mathrm{em}$ $\mathrm{P} 5$. A granulometria das areias do berma do setor SW variou consideravelmente ao longo do ano, apresentando modas entre 0,5 (areia grossa) e 2 (areia media) phi. Exceções aos meses de junho e agosto, que apresentaram um afinamento da moda (2,5 phi). Estas variações podem estar relacionadas à maior competência hidráulica das ondas e um possível fornecimento sedimentar pela desembocadura do corpo d'água próximo a estação amostral.

As areias do berma da Estação P2 apresentaram distribuição granulométrica bastante similar ao longo do tempo, com modas em areia fina (2 phi) para todos os meses, exceto fevereiro, o qual apresentou pior grau de seleção em relação aos demais. A granulometria da face também se mostrou praticamente homogênea, com modas entre 2,5 e 3 phi. O setor Central apresentou modas granulométricas para berma em torno de 2,5 phi para todos os meses, exceto para o mês de junho, apresentando moda em 3 phi. A granulometria da face sofreu maior mobilidade, apresentando modas entre 2 e 3,5 phi.
Para o setor NE, P4 apresentou baixa mobilidade, tanto para berma quanto para face praial, o que sugere certa estabilidade do setor em relação à sazonalidade. A granulometria do berma apresentou características simétricas em relação à distribuição, enquanto a face apresentou assimetria positiva, indicando engrossamento dos grãos. Disto pode-se inferir uma possível retirada de material fino pelas ondas, ou depósito de grossos pelo espraiamento, uma vez que mais energia é capaz de transportar material de maior equivalência hidráulica. Já a estação P5 apresentou muito pouca mobilidade, com distribuição simétrica ao longo de todos os meses de coleta. Quanto à face praial, a Estação apresentou assimetria negativa no verão e inverno, mantendo-se simétrica nos demais meses. Para o mês de outubro notou-se um engrossamento de grãos. A face de P5 apresentou certa mobilidade ao longo dos meses de coleta. Isto pode estar relacionado à distribuição de sedimentos, ora provenientes da deriva longitudinal, ora do transporte transversal como agente de seleção e também sedimentos provenientes das ondas de leste, que difratam e depositam.

\subsubsection{Tipologia praial}

Os resultados obtidos para o cálculo da tipologia da praia, em condições de tempo bom e tempestade estão representados na Quadro 3. Em condições de maior energia de onda, considerados como condições de tempestade, a praia apresentou homogeneidade no estado dissipativo. Para condições de tempo bom, os estados modais mostraram-se intermediários, variando entre Banco e Calha Longitudinal e Terraço de Baixa Mar.

\subsubsection{Deriva Litorânea}

No verão, o setor NE apresentou largura de perfil maior que o setor SW, bem como menor inclinação e diminuição da granulometria, o que também pôde ser constatado para o mês de inverno. Entretanto, a variação textural entre os perfis apresentou significativa diferença entre os meses de inverno e verão.

No verão, a direção da corrente de deriva litorânea apresentou sentido $\mathrm{SW}$ - NE, com erosão na 
Quadro 3 - Estados modais da praia, conforme modelo de Dean (1973) e Wright et al (1985). bcl: Banco e Calha longitudinal; tbm: Terraço de baixa Mar; bpr: Banco de praia rítmico; dissip: Dissipativo.

\begin{tabular}{|c|c|c|c|c|c|c|c|c|c|c|}
\hline \multirow[b]{2}{*}{ Campanha } & \multicolumn{2}{|c|}{$P 1$} & \multicolumn{2}{|c|}{$P 2$} & \multicolumn{2}{|c|}{ P3 } & \multicolumn{2}{|c|}{ P4 } & \multicolumn{2}{|c|}{ P5 } \\
\hline & dez/08 & jun/08 & dez/09 & jun/09 & dez/08 & jun/09 & dez/08 & jun/09 & dez/08 & jun/09 \\
\hline Diâmetro Médio da Face $(\varphi)$ & 2,37 & 1,20 & 2,50 & 2,55 & 2,34 & 2,53 & 2,62 & 2,52 & 2,94 & 2.9 \\
\hline$W s(\mathrm{~cm} / \mathrm{s})$ & 3,3 & 6 & 3 & 3,1 & 3,2 & 3,1 & 2,7 & 3,1 & 2,6 & 2,6 \\
\hline$\Omega$ (Tempo Bom) & 5,05 & 2,77 & 5,55 & 5,37 & 5,20 & 5,37 & 6,17 & 5,3 & 6,41 & 6,4 \\
\hline$\Omega$ (Tempestade) & 6,85 & 3,76 & 7,53 & 7,29 & 7,06 & 7,29 & 8,3 & 7,29 & 8,69 & 8,6 \\
\hline Estado Morf.da Praia (Tempo bom) & $B C l$ & Tbm & Dissip & Dissip & $\mathrm{BCl}$ & Dissip & Dissip & Dissip & Dissip & Dissip \\
\hline Estado Morf. da Praia (Tempestade) & Dissip & $B p r$ & Dissip & Dissip & Dissip & Dissip & Dissip & Dissp & Dissip & Dissip \\
\hline
\end{tabular}

Estação de maior energia (P1), transporte através das Estações P2, P3 e P4, e deposição no ponto de menor energia P5 (Figura 11). As Estações P2, P3, P4 comportaram-se como zona de by-pass, apenas transportando o sedimento proveniente, não apresentando características de deposição ou erosão.

No período de inverno, os resultados mostraram P1 ainda com alta energia de ondas, comportando-se de forma erosiva, fonte de sedimentos. A Estação P2 apresentou tendência de transporte, enquanto em P3 ocorreu deposição proveniente de P1. A estação P4 apresentou tendência erosiva, depositando sedimentos em P3 e P5, os quais apre- sentaram baixa energia de ondas.

\subsubsection{Integração Morfodinâmica da Praia}

A partir da integração dos dados infere-se que a Praia do Morro é formada predominantemente por sedimentos finos e muito finos (media 2,7 phi), com baixo gradiente de inclinação da face praial, (diminui de SW para NE). A maior granulometria encontrada nas Estações no setor SW da praia está possivelmente relacionada à competência das ondas em mobilizar e transportar os finos por deriva, deixando os grossos como residuais.

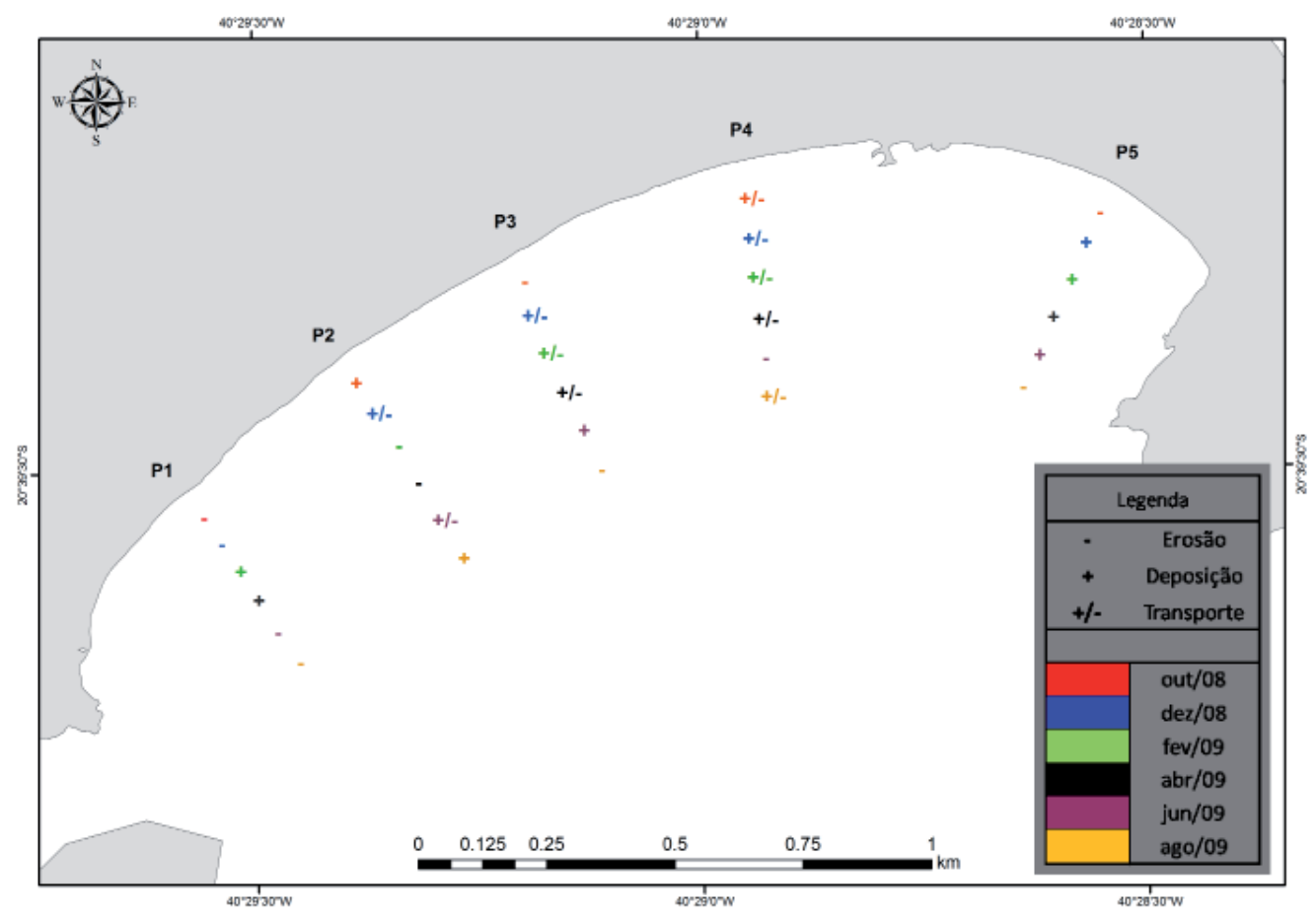

Figura 11 - Correntes de deriva litorânea de acordo com o mês amostrado, através do método Tagaart e Schwarts (1988), modificado por Souza (1997). Os resultados se referem à mesma região submersa longitudinal à praia, somente diferem as datas da amostragem. 
$\mathrm{O}$ afinamento dos grãos $\mathrm{r}$ umo ao NE ocorre pela redução da energia de onda, resultando no processo de zonação granulométrica, conforme descrito por Komar (1976). Os grãos finos que são transportados transversal e longitudinalmente depositam-se na porção caracterizada pela zona de sombra do promontório adjacente, conforme sugerido por Short (1999) e Short e Masselink (1999) e corroborado pela seleção granulométrica de praias de enseada encontrados por Oliveira et al (2009) na Praia Pântano Sul, SC e por Vilas Boas e Bittencourt (1992) , na costa leste da Baía de Todos os Santos, BA.

Por outro lado, a presença de areias mais grossas na porção sul pode sugerir o aporte do estuário da Baía de Guarapari à região praial, já que a praia imediatamente ao sul apresenta esta granulometria e ainda, este padrão de afinamento dos grãos em acordo com a deriva em enseadas foi verificado por Klein et al (2005) nas proximidades de desembocadura fluvial.

Da mesma maneira, as maiores variações espaciais dos parâmetros morfodinâmicos como a mobilidade dos perfis, o volume e largura da praia, além das alturas das ondas na arrebentação e a granulometria das areias, são observadas em praias com curvaturas mais altas. Com a diminuição da curvatura, as alterações dos parâmetros morfodinâmicos são menores ao longo do perímetro da enseada (Klein et al. 2002). Em praias com processo rotacional dos sedimentos, isto é, inversões no transporte de sedimentos observados entre os dois limites do arco praial, a porção central é mais retilínea e tende também, a ser mais estável. Comportamento semelhante ao verificado na praia do Morro, foi também observado por Araújo et al (2010) e Albino et al (1996) e em outras praias brasileiras em forma de enseada.

A variação sazonal das condições de ondas causaram alterações significativas de volume entre os meses de verão e inverno, mais precisamente representativos de tempo bom (deposição) e frentes frias (erosão), o que pode ser indicativo de resposta sedimentar a ciclicidade dos eventos climáticos como moduladores do prisma praial. O modelo utilizado de transporte longitudinal apresentou predomínio de deposição na Estação P5, assim como predomínio de erosão na Estação P1, o que sugere uma tendência de transporte sentido SW - NE ao longo de todo o ano, destacadamente no mês de dezembro. Este transporte pode ser validado pela diferença significativa do gradiente de energia das ondas, o qual diminui progressivamente sentido NE. Ainda, uma possível validação do modelo pode ser aferida pelas variações topográficas observadas nos perfis, as quais são consensuais aos padrões obtidos de transporte. $\mathrm{O}$ mês de junho apresentou erosão no setor NE, coerente com o grau de exposição do segmento em relação à incidência de ondas provenientes de sistemas frontais $(\mathrm{S} / \mathrm{SE})$.

Comparando-se a mobilidade dos perfis de praia aos resultados dos modelos de transporte, observa-se que outras células de circulação de sedimentos podem co-existir decorrentes das inversões das direções e alterações das ondas dentro da enseada, o que evidencia a dinâmica do sistema oscilatório na enseada. $\mathrm{O}$ modelo conceitual de sistema oscilatório de enseada foi proposto por Ranasinghe et al. (2004) para as praias de enseada da Austrália, onde foi identificado que, sob o processo rotacional, havia períodos de recuo ou acresção na praia. A flutuação temporal e espacial das alturas das ondas age paralelamente no transporte longitudinal e transversal.

A praia apresentou estados modais variando entre dissipativo, em simulações de eventos de tempestade e estados intermediários subsequentes a este (Banco e Calha Longitudinal) em simulações de tempo bom, o que sugere e endossa a atuação das trocas sedimentares transversais intensificadas por ocasião de ondas mais altas (RANASINGHE et al, 2004).

Estados modais que sugerem a retenção de sedimentos na porção mais próxima a costa foram encontrados na porção SW, como Terraço de Baixa Mar e Banco e Calha Longitudinal. A granulometria, a inclinação da praia e a carga sedimentar do estuário são os fatores responsáveis por este resultado.

Em termos gerais, a praia responde aos eventos cíclicos de maior ou menor energia hidrodinâmica. Seu grau de exposição à incidência de ondas de eventos de sistemas frontais a deixa mais vulnerável ao recuo nos meses de maior frequência de frentes frias, a saber, de abril a agosto, com 
trocas transversais de sedimento. Em condições de tempo bom, a praia reconstitui-se, exibindo um perfil mais construtivo.

Paralelamente, há indicação de uma resultante de transporte de sedimentos para sul, entretanto, apresentando ainda tipologia de padrões erosivos, basicamente devido às características sedimentares.

\subsection{Avaliação da mobilidade em planta}

\subsubsection{Planta modelada}

A Praia do Morro apresenta assimetria da linha de costa, típica de uma praia de enseada, como pressuposto por Silvester e Hsu (1997), com curvatura mais acentuada próxima ao promontório principal, uma seção central suavizada e um setor mais retilíneo no qual as ondas geralmente incidem paralelas à costa.

A adoção de dois pontos de difração das ondas: o promontório $\mathrm{S}$ difratando predominantemente as ondas de $\mathrm{SE}$ e o promontório a $\mathrm{N}$, as ondas as ondas de NE, demostrou a adequação da aplicação do modelo à praia do Morro. Contudo, os resultados do modelo para os dois arcos extremos indicaram diferentes estados de equilíbrio (Figura 12).

No setor SW a planta modelada apresentou-se mais recuada quando comparada à configuração atual, sendo classificada em estado equilíbrio dinâmico.

A presença do aporte fluvial e, possível

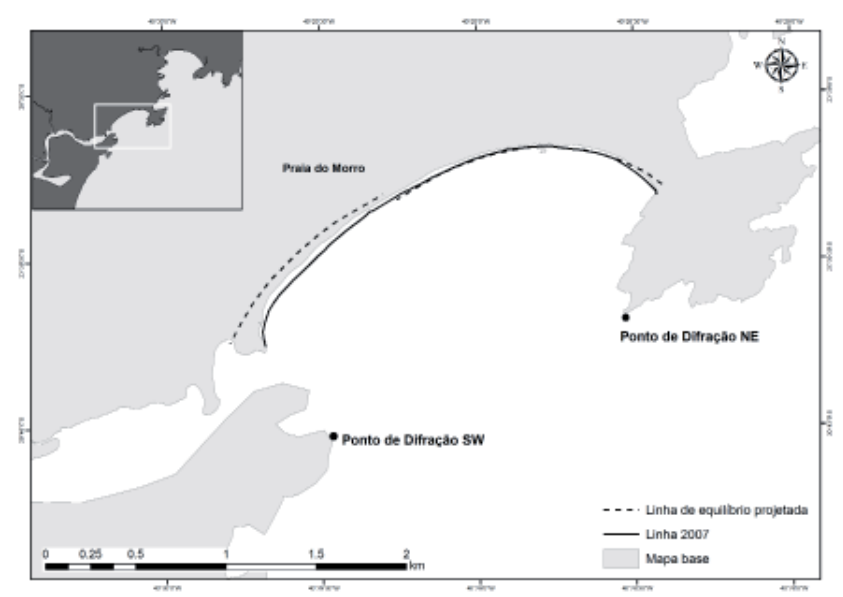

Figura 12 - Linha de costa prevista através do modelo parabólico (Meppe) para o arco da Praia do Morro, em relação ao ponto de difração SW e NE da praia, e em relação à linha de costa vetorizada de 2007, para fins de comparação. interferência no padrão das ondas na proximidade da desembocadura do canal favorece a deposição dos sedimentos neste setor. A ação das ondas difratadas tenderiam a recuar a linha de costa. A zonação granulométrica dos sedimentos e mobilidade dos perfis valida a classificação encontrada e o possível processo atuante. Desse modo, a praia estaria em condições de equilíbrio dinâmico, sob influência do canal estuarino, onde o aporte sedimentar sazonal induz a área a uma nova adaptação de sua simetria, onde a maior mobilidade dos perfis e a tendência ao recuo seria a evolução progressiva para um estado de equilíbrio estático.

Já no setor NE, a planta modelada apresentou-se bem próximo a planta real da praia, o que lhe confere um estado de equilíbrio estático. Mesmo com a facilidade da resultante da deriva de sul ser depositada neste setor, a similaridade da planta modelada e a real sugere outros processos que não a deriva litorânea. Desta forma, reafirma-se os processos transversais e as diferentes células atuando em conjunto e ainda os efeitos do rotacional ao longo de toda a praia.

Já a deriva longitudinal predominante, sentido SW - NE contribui para deposição de areias de baixa granulometria no setor NE, o que provavelmente resulta na neutralidade deste em relação ao input sedimentar, condição para o estado de equilíbrio estático encontrado.

\subsubsection{Mobilidade histórica da linha de praia}

A mobilidade da linha de costa se mostrou mais significativa no intervalo decadal (1970-1978) do que no multidecadal (1970-2007), as quais foram basicamente constantes ao longo do intervalo.

As áreas de maior variação percebidas correspondem ao intervalo decadal, quando foram mais significativas nos setores $\mathrm{SW}$ e NE do arco praial (Figura 13), principalmente nos transectos 1 a 10 e 54 a 60. No setor Central, entre os transectos 13 a 50, as variações mantiveram-se basicamente constantes, apresentando certo padrão entre os transectos 20 a 45, em relação às amplitudes de 1970 a 1978 e 1978 a 2007.

Os menores valores de variação encontram-se nos transectos 13-15, que representam a formação 


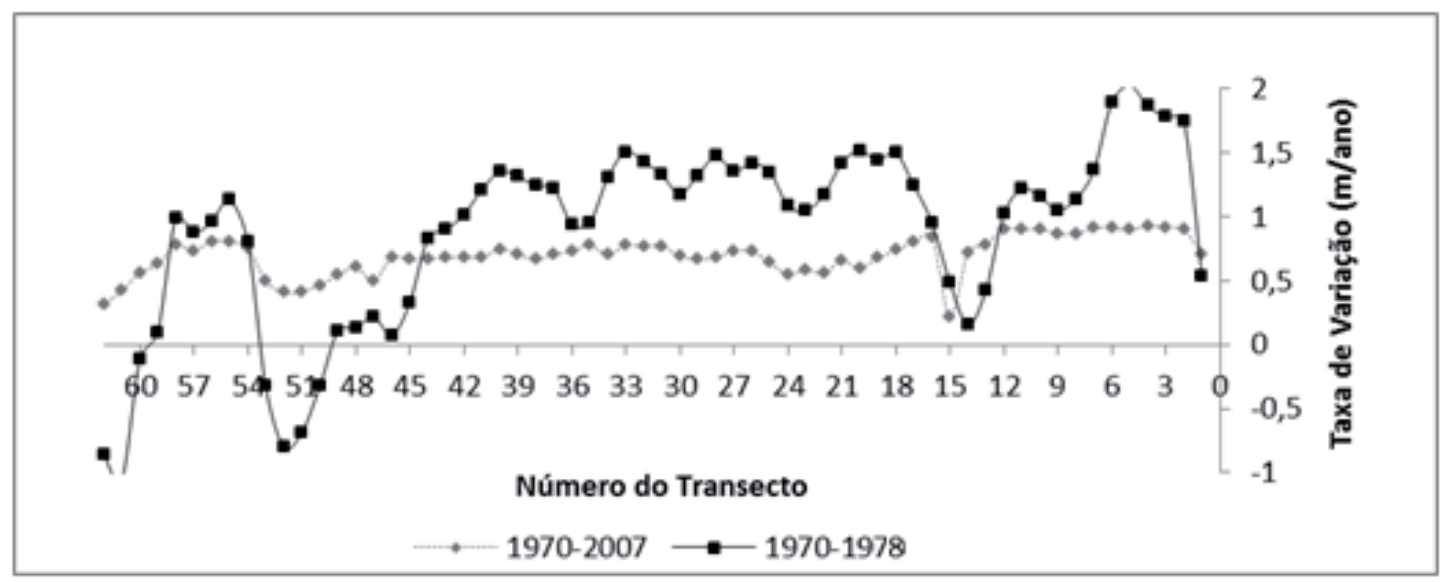

Figura 13 - Taxa de variação por transecto em relação aos anos avaliados. Valores negativos indicam deposição.

de um tômbolo, cuja deposição sedimentar ao longo dos anos fez com que a linha de espraiamento demonstrasse menor mobilidade. Os valores negativos, indicativos de deposição sedimentar, nos transectos do setor SW (49 - 53) e $(60$ - 61) aparecem entre as décadas de 1970 e 1978.

A avaliação da mobilidade da praia na escala decadal (1970 - 1978) sugere uma adequação planar aos processos morfodinâmicos de curta escala, diagnosticados neste trabalho pelo modelo de equilíbrio planar e pelas observações morfodinâmicas em campo. Desse modo, as maiores variações observadas nos setores das extremidades da praia, representam o ajuste do arco praial aos processos de difração das ondas na enseada, em consonância com o clima de ondas atual, ou seja, intensidades semelhantes de alturas e períodos provenientes dos quadrantes $\mathrm{S} / \mathrm{SE}$, gerando como consequência maior erosão do setor SW e o transporte longitudinal por decaimento energético sentido NE, com deposição dos finos. De forma análoga, as resultantes rotacionais foram percebidas em uma menor escala temporal, justificando a maior mobilidade encontrada ao longo de todo o arco.

Já na escala multidecadal (1970 - 2007), menores taxas de variação puderam ser observadas em relação à assimetria do arco praial, situação diferente à encontrada no período decadal. Tal resultado pode sugerir a adequação morfodinâmica da praia à variações em uma escala diferente de eventos, quando os fatores que predominam na modelagem da linha de costa são de larga escala, somente sendo observados em análises deste tipo. $\mathrm{O}$ recuo mais homogêneo em relação a todo arco praial observa- do neste trabalho para a escala multidecadal pode indicar variações climáticas regionais, de meso a larga escala, onde variações regionais no nível marinho, como marés e intensificação do clima de ondas fazem com que haja predomínio de trocas transversais na modelagem da praia, conforme postulado pelo modelo de Bruun (1962), o qual propõe um recuo basicamente linear à linha de costa a partir de um aumento de nível marinho. Em se tratando de uma praia de enseada, o empilhamento resultante da ação das ondas ao longo das décadas poderia ser o gatilho do processo linear de recuo.

\subsection{Mobilidade e Erosão da Enseada da Praia do Morro ao longo das décadas}

A Praia do Morro vem ao longo das décadas apresentando um aparente processo de retrogradação de sua linha de costa.

A retrogradação da linha de praia nas últimas décadas e suas diferentes taxas de mobilidade atestam sua escala temporal de resposta aos processos físicos atuantes. Como previsto pelo modelo parabólico, a praia aparenta um comportamento de ajuste morfodinâmico em relação à diferentes graus de exposição ao clima de ondas e suas transformações em águas rasas. As características físicas sob a perspectiva regional, tais como baixo aporte continental, planície costeira e plataforma estreita, e orientação da praia exposta a eventos energéticos de sistemas frontais são também parâmetros que exercem influencia sobre seu comportamento erosivo.

Trata-se de uma praia de enseada, situada entre dois promontórios rochosos, que apresenta na 
forma planar assimetria da linha de costa, com uma curvatura mais acentuada na extremidade do promontório NE, suavizada e quase retilínea à medida que se afasta deste, sentido SW. De fato, o modelo utilizado de transporte longitudinal (TAGGART E SCHWARTZ, 1988) apresentou predominância de deposição no setor NE, assim como predominância de erosão no setor SW, o que sugere uma tendência de transporte sentido SW - NE ao longo do ano. A resultante da deriva longitudinal apresentou-se conforme descrito por Hsu et al (2008) sob condições semelhantes na praia de Balneário Comboriu (SC), e Vargas et al (2002) na baía de Imbituba (SC).

Os processos de urbanização da orla e desenvolvimento urbano possivelmente corroboraram para a intensificação da erosão da praia, apesar de não terem sido mensurados no escopo deste trabalho. De todo modo, a ação dos diversos sangradouros e construção de calçadão sobre a faixa de areia, pode diminuir o estoque disponível para as trocas naturais entre praia emersa e submersa, conforme sugerido por Muehe (2001).

Vale observar que a Praia do Morro passa atualmente por um processo de reurbanização de sua orla, uma vez destruída pelo evento de ressaca citado neste trabalho. A reurbanização poderá recuperar a estética da paisagem e poderá mitigar os efeitos sobre o balanço sedimentar, mas não foi previsto projetos de engordamento de praia.

Variações de alta frequência no balanço sedimentar ao longo da praia, tais como mudanças naturais no regime de ondas, podem intercalar diferentes tendências entre deposição e erosão ao longo do mesmo arco praial, notadamente observáveis quando de sua análise em diferentes escalas temporais, conforme também observado por Mazzer e Dillemburg (2009) nas praias de Solidão e Matadouro em Santa Catarina.

\section{Conclusão}

O trabalho procurou utilizar as ferramentas disponíveis na pesquisa em morfodinâmica praial na intenção de investigar as variações da praia em diferentes escalas de tempo. Sob a égide da geomorfologia costeira, a escala temporal é fundamental para o diagnóstico e avaliação do sistema.
Os resultados obtidos em relação à escala de um ano demonstraram claramente as trocas sedimentares entre os setores da praia, confirmando o mecanismo rotacional previsto para praias de enseada. No entanto, com base somente nesta escala, não seria possível inferir tendências erosivas ou deposicionais na praia como um sistema contínuo e integrado. A partir da análise na escala de uma década, pode-se sugerir um processo erosivo mais intenso, mais dinâmico, com grandes trocas longitudinais e ajustes planares à difração das ondas incidentes entre os setores assim como maior instabilidade.

A partir da análise do intervalo multidecadal percebe-se o processo de ajuste para novo estado de equilíbrio, no qual as variações aparecem mais suaves e o sistema de praia apresenta um recuo mais homogêneo e taxas relativamente constantes, indicadores de variações climáticas de nível regional e maior escala de eventos.

Os resultados sugerem a importância das avaliações em diferentes escalas de tempo para a obtenção de informações mais confiáveis sobre os sistemas naturais. O monitoramento é fundamental nestas avaliações, e deve ser tomado como parâmetro base para a tomada de decisões em relação à futuros projetos de intervenções costeiras ou previsões climáticas.

\section{Referências}

ABSALONSEN, L.; TOLDO Jr., E. E. A Influência da Inflexão Costeira na Variabilidade da Linha de Praia em Mostardas - RS. Revista Pesquisas em Geociências, v. 34, n.1, p.3-18, 2006.

ALBINO, J. Morphodynamics and coastal processes on Baleia, fruta and sol beaches, State of Espírito Santo, Brazil. Anais da Academia Brasileira de Ciências, v. 68, n.3, p.425-438, 1996.

ALBINO, J.; OLIVEIRA, R.; MAYA, L.; ALENCASTRE, K. Processos atuais de sedimentação marinha e praial do litoral de Vitória, ES. Relatório n. 1982506/2000. Prefeitura Municipal de Vitória, FACITEC:Vitória, Espírito Santo, 2001.

ARAÚJO, R.S; SPROVIERI, F.C.; FREITAS, D.; 
KLEIN, A.H.F. Variação da Morfologia Praial e Identificação de Zonas de Erosão Acentuada (ZEA) na enseada do Itapocorói - SC. Brazilian Journal of Aquatic Science and Technology, v.14, n.1, p.29-38, 2010.

BRUUN, P. Sea-level rise as a cause of shore erosion. Proceedings of the American Society of Civil Engineers. Journal of the Waterways and Harbors Division, v.88, p.117-130, 1962.

CENTRO de Previsão do Tempo e Estudos Climáticos (CPTEC). Previsão de ondas para região de Guarapari. Disponível em: http://ondas. cptec.inpe.br/. Acessado em: 12/abril/2010.

DEAN, R G. Heuristic models of sand transport in the surf zone. In: First Australian Conference on Coastal Engineering, 1973: Engineering Dynamics of the Coastal Zone. Sidney, N.S.W.: Institution of Engineers, Australia. p. 215-221, 1973.

DIRETORIA de Hidrografia e Navegação. Tábua de Marés. Terminal de Ubu. Disponível em: $<w w w$. dhn. mar.mil.br>. Acesso em: 06/maio/2009.

FOLK, R. F. Petrology of Sedimentary rocks. Hemphill Publishing Company. Austin, Texas, 184 p., 1968.

FOLK, R. L.; WARD, W. C. Brazos River Bar: A study in the significance of grain size parameters. Journal of sediment petrology,v.27, n.1, p.3-26, 1957.

HSU, J.R.C.; EVANS, C. Parabolic bay shapes and applications. Proceedings, Institution of Civil Engineers, v. 87, n. 4, p. 557-570, 1989.

HSU, J.R.C.; BENEDET, L; KLEIN, A. H. F.; RAABE, A. L. A.; TSAI, C.P.; HSU, T.W. Appreciation of static bay beach concept for coastal management and protection. Journal of Coastal Research, v. 24, n. 1, p.195-215, 2008.

INCAPER. Programa de assistência técnica e extensão rural PROATER 2011 - 2013. Guarapari. Disponível em http://www.incaper. es.gov.br/proater/municipios/Centro cerrano/ Guarapari.pdf. Acessado em: 09/setembro/2013.

INSTITUTO BRASILEIRO DE GEOGRAFIA E ESTATÍSTICA - IBGE. Censo demográfico 2000: agregados preliminares. Espírito Santo, 2010.
KLEIN, A. H. F.; BENEDET FILHO, L; SCHUMACHER, D. H. Short-term beach rotation processes in distinct headland bay beach systems. Journal of Coastal Research, v. 18, n.3, p. 442458, 2002.

KLEIN, A.H.F.; SILVA, G.M; FERREIRA, O; DIAS, A. Beach sediment distribution for a headland bay coast. Journal of Coastal Research, v.SI, n.42, 285-293, 2005.

KOMAR, P.D. Beach Process and sedimentation. Englewood Cliffs, N.J.: Prentice-Hall, 429p., 1976.

MAZZER, A. M.; DILLEMBURG, S. Variações temporais da linha de costa em praias arenosas dominadas por ondas do sudeste da Ilha de Santa Catarina (Florianópolis, SC, Brasil). Pesquisas em Geociências, v.36, n.1, p.117-135, 2009.

MUEHE, D. Critérios Morfodinâmicos para o Estabelecimento de Limites da Orla Costeira para fins de Gerenciamento. Revista Brasileira de Geomorfologia, v.2, n.1, p.35-44, 2001.

MUEHE, D. Geomorfologia Costeira. In: CUNHA, S. B.; GUERRA, A. J. T. (Org.). Geomorfologia - Exercícios, Técnicas e Aplicação. Bertrand Brasil S.A., Rio de Janeiro, p.191-238, 1996.

OLIVEIRA, U.R; BARLETTA, R.C; PEIXOTO, J.R.V; HORN FILHO, N.O.Características Morfodinâmicas da praia do Pântano do Sul, Ilha de Santa Catarina, Brasil. Pesquisas em Geociências, v.36, n.3, p.237-250, 2009.

PEEL, M. C; FINLAYSON, B. L.; MCMAHON, T. A. Updated world map of the Köppen-Geiger climate classification. Hydrology and Earth System Sciences, v.11, p.1633-1644, 2007.

PIUMBINI, P.P. Clima de Ondas de Gravidade e Estado de Agitação Marítima em Ambientes Marinhos no Espírito Santo. Dissertação de Mestrado em Engenharia Ambiental, Universidade Federal do Espírito Santo, p.108, 2009.

RANASINGHE, R; MCLOUGHLINA, R; SHORT, A; SYMONDS, G. The Southern Oscillation Index, wave climate, and beach rotation. Marine Geology, v.204, n.3-4, p.273-287, 2004.

SHORT, A.D. Handbook Of Beach And Shoreface 
Morphodynamics. Jonh Wiley, Chichester, 379p., 1999.

SHORT, A.D.; MASSELINK, G. Embayed and Structurally Controlled Beaches. In: SHORT, A.D. Hanbook of Beaches and Shoreface Morphodynamics. John Wiley \& Son, Chichester, p.230-250, 1999.

SILVESTER, R.; HSU, J. R. C. Coastal Stabilization. In: Advanced Series on Ocean Engineering. v. 14, World Scientific Publishing, Singapore, 1997.

SOUZA, C. R. G. Determination of net shoredrift cells based on textural and morphological gradations along foreshore sandy beaches. Journal of Coastal Research, v.50, p.620-625, 2007.

TAGGART, B. E.; SCHWARTZ, M.L. Net shore drift direction determination: a systematic approach. Journal of shoreline management, v.3, n.4, p.285-309, 1988.

THIELER, E. R.; HIMMELSTOSS, E. A.; ZICHICHI, J. L.; ERGUL, A. Digital Shoreline
Analysis System (DSAS) version 4.0-An ArcGIS extension for calculating shoreline change. U.S. Geological Survey Open-File Report, 2008.

VARGAS, A.; RAABE, A.L.A.; KLEIN, A.H.F. Sistema Computacional para Aplicação do Modelo Parabólico de Praias de Enseada. Revista Brasileira de Geomorfologia, v.3, n.1, p.11-19, 2002.

VILAS BOAS, G. S.; BitTENCOURT, A. C.S.P. Variação da energia e sua repercussão nas características composicionais e texturais em sedimentos praiais atuais: exemplo da costa leste da baía de todos os santos, Bahia, Brasil. Revista Brasileira de Geociências, v.22, n.3, p.311-320, 1992.

WRIGHT, L.D; SHORT, A.D; GREEN, M.O. Short term changes in the morphodinamic states of beaches and surf zones: An empirical predictive model. Marine Geology, v.62, n.3-4, p.339-364, 1985. 